\title{
Infrared cameras overestimate skin temperature during rewarming from cold exposure
}

\begin{abstract}
Matthew J Maley ${ }^{1,2 *}$, Andrew P Hunt ${ }^{3}$, Aaron J E Bach ${ }^{4}$, Clare M Eglin², Joseph T Costello ${ }^{2}$

${ }^{1}$ Department of Sport, Institute of Human Sciences, University of Wolverhampton, Walsall, UK. ${ }^{2}$ School of Sport, Health and Exercise Science, University of Portsmouth, Portsmouth, UK. ${ }^{3}$ Institute of Health and Biomedical Innovation, School of Exercise and Nutrition Sciences, Queensland University of Technology, Brisbane, Australia. ${ }^{4}$ National Climate Change Adaptation Research Facility, Griffith University, Gold Coast, Australia.
\end{abstract}

${ }^{*}$ Corresponding author

m.maley2@wlv.ac.uk 


\section{Abstract \\ Objective}

The primary aim of this study was to assess the accuracy of an infrared camera and that of a skin thermistor, both commercially available. The study aimed to assess the agreement over a wide range of skin temperatures following cold exposure.

\section{Methods}

Fifty-two males placed their right hand in a thin plastic bag and immersed it in $8{ }^{\circ} \mathrm{C}$ water for 30 minutes whilst seated in an air temperature of $30{ }^{\circ} \mathrm{C}$. Following hand immersion, participants removed the bag and rested their hand at heart level for ten minutes. Index finger skin temperature $\left(T_{s k}\right)$ was measured with a thermistor, affixed to the finger pad, and an infrared camera measured $1 \mathrm{~cm}$ distally to the thermistor. Agreement between the infrared camera and thermistor was assessed by mean difference (infrared camera minus thermistor) and $95 \%$ limits of agreement analysis, accounting for the repeated measures over time. The clinically significant threshold for $\mathrm{T}_{\text {sk }}$ differences was set at $\pm 0.5^{\circ} \mathrm{C}$ and limits of agreement $\pm 1^{\circ} \mathrm{C}$.

\section{Results}

As an average across all time points, the infrared camera recorded $T_{\text {sk }} 1.80$ (SD 1.16) ${ }^{\circ} \mathrm{C}$ warmer than the thermistor, with $95 \%$ limits of agreement ranging from $-0.46{ }^{\circ} \mathrm{C}$ to $4.07^{\circ} \mathrm{C}$. 


\section{Conclusion}

Collectively, the results show the infrared camera overestimated $T_{\text {sk }}$ at every time point following local cooling. Further, measurement of finger $\mathrm{T}_{\text {sk }}$ from the infrared camera consistently fell outside the acceptable level of agreement (i.e. mean difference exceeding $\pm 0.5{ }^{\circ} \mathrm{C}$ ). Considering these results, infrared cameras may overestimate peripheral $\mathrm{T}_{\text {sk }}$ following cold exposure and clinicians and practitioners should, therefore, adjust their risk/withdrawal criteria accordingly.

\section{Keywords}

Infrared thermography; temperature measurement; thermoregulation; cold exposure; instrument validity 


\section{Introduction}

Measurement of skin temperature $\left(T_{\text {sk }}\right)$ is routinely conducted in research investigating human responses to environmental extremes. Measuring $T_{\text {sk }}$ enables researchers to profile and calculate a wide variety of responses. Examples include mean body temperature (Hardy and Du Bois, 1938; Jay et al., 2007), body heat content (Burton, 1935), and relatively newer calculations such as the adaptive physiological strain index (Buller et al., 2018; Hunt et al., 2019).

Measurement of $T_{\text {sk }}$ may be conducted with a wide variety of devices that are broadly classified as conductive or infrared. Conductive devices, primarily thermistors, are often the preferred method for measuring $T_{\text {sk }}$ (Bach et al., 2015b, 2015a; James et al., 2014). Most thermistor-based systems have a negative temperature coefficient. That is, their resistivity decreases with increasing temperature. In a thermistor-based system, a signal of $35 \mathrm{mV}$ per ${ }^{\circ} \mathrm{C}$ is typical; nearly 1000 times greater than a thermocouple-based system (Bull, 2008). Thermistors are known for their long-term stability (Togawa, 1989), producing an error of $\sim 0.1^{\circ} \mathrm{C}$ (Bull, 2008). In contrast, infrared thermography is a noncontact technique, which transforms the energy radiated from objects in the infrared band into an electronic video signal that can be displayed on a computer and stored (Hildebrandt et al., 2010; Meola and Carlomagno, 2004).

Infrared cameras have added advantages over conductive devices. For example, they are able to capture (image or video) and store large quantities of data, meaning different areas of skin can be analysed retrospectively (Fernández-Cuevas et al., 2015; Moreira et al., 2017). In contrast, conductive devices are fixed to a specific skin site. 
Additionally, most conductive devices are wired and, therefore, participants or patients are tethered to a data logger and their movement potentially restricted.

As a result of the improved accuracy of infrared devices over recent years, and despite the increased cost relative to conductive devices, their use has become more frequent in human physiology research. Example studies include local cold exposure (Brändström et al., 2008; Costello et al., 2012b, 2012a; Hope et al., 2014), identification of sporting injuries (Hildebrandt et al., 2010), testing individuals with non-freezing cold injuries (NFCl) (Ahle et al., 1990; Eglin et al., 2013) or Raynaud's phenomenon (Ring and Ammer, 2012; Shepherd et al., 2019), as well as during medical operations (Mercer et al., 2010). However, under controlled laboratory conditions during exercise and/or warm environmental conditions, thermal imaging technology to date has shown not to be acceptable; that is $T_{s k}$ is under- or overestimated compared with a number of conductive devices (Bach et al., 2015a, 2015b; Buono et al., 2007; Fenemor et al., 2019; James et al., 2014).

Even though infrared cameras have been utilised to measure $T_{\text {sk }}$ during cold exposure (Costello et al., 2012a; Hope et al., 2014; Maley et al., 2014), the accuracy of infrared cameras for measuring $\mathrm{T}_{\mathrm{sk}}<33{ }^{\circ} \mathrm{C}$ is not well established. Several studies have compared $T_{\text {sk }}$ results between an infrared device and a conductive device during cold exposure; however, these studies are limited by sample size, the methodology of cold application and incomplete statistical analysis to properly assess the validity of infrared devices (Buono et al., 2007; Kelechi et al., 2011; Korukçu and Kilic, 2009). 
If $\mathrm{T}_{\mathrm{sk}}$ is cooled to $<15^{\circ} \mathrm{C}$ for a prolonged period then the risk of peripheral cold injuries is significantly increased (Eglin et al., 2013; House et al., 2000; Maley et al., 2017, 2014; Thomas and Oakley, 2001). Considering this, the accuracy of infrared devices in measuring $T_{\text {sk }}$ is paramount in order to not expose an individual to an increased risk of peripheral cold injuries. Given the need for valid monitoring of cooled Tsk across a wide range of sport, medical and occupational settings, this investigation set out to compare the agreement of $\mathrm{T}_{\mathrm{sk}}$ between a conductive device with that of a non-contact infrared device during recovery from cold exposure. 


\section{Methods}

This study was given ethical approval from the University of Portsmouth Science Faculty Ethics Committee and complied with standards set in The Declaration of Helsinki (2013). The participants were made aware of the purpose, procedures and risks of the study before giving their informed written consent. Fifty-two male participants volunteered in the study; their physical characteristics are as follows (mean [SD]): age 20 [2] years, height of $177.5[7.7] \mathrm{cm}$, body mass of 75.5 [13.2] kg and hand length of 20.3 [1.2] $\mathrm{cm}$. Participants' height and body mass were measured using a stadiometer (Leicester, Bodycare, UK) and digital weighing scales (Ohaus I-10, Ohaus Corporation, USA), respectively. Length of participants' right hand was measured using a segmometer (Segmometer 4, Rosscraft, Canada).

Participants entered the climate controlled chamber (mean [SD] dry-bulb: $30.3\left[0.9{ }^{\circ} \mathrm{C}\right.$, wet-bulb: $22.9\left[0.9{ }^{\circ} \mathrm{C}\right.$, wet-bulb globe temperature: $25.1\left[0.9{ }^{\circ} \mathrm{C}\right.$ ) and rested in a semirecumbent position for 25 minutes whilst being instrumented. During the 25 minute rest period, a skin thermistor (Type EUS-U, Grant Instruments, UK), connected to a data logger (Squirrel 2020, Grant Instruments, UK), was affixed onto the participant's second finger pad of the right hand using a small piece of breathable tape (Transpore Tape, $3 \mathrm{M}^{\mathrm{TM}}$, USA). Participants then placed their hand into a plastic bag, immersed it to the styloid process in a water bath maintained at $35.0[0.2]{ }^{\circ} \mathrm{C}$ for five minutes. Following this, participants removed their hand from the water, still within the plastic bag, and immediately placed it in a stirred water bath maintained at $8.1\left[0.1{ }^{\circ} \mathrm{C}\right.$. After 30 minutes of cooling, participants removed their hand from the water bath and plastic bag to allow spontaneous rewarming for ten minutes. During this period, participants rested their 
hand at the level of the heart. A calibrated infrared camera (A320G, FLIR Systems, UK) was positioned on a level tripod perpendicular to the participant's hand at a distance of one meter in line with published guidelines (Moreira et al., 2017). The camera was calibrated within 12 months of use. Data were recorded to dedicated software (ThermaCAM ${ }^{\mathrm{TM}}$ Researcher, FLIR Systems, UK) to allow offline analysis. Emissivity (0.98) and distance $(1 \mathrm{~m})$ was set in object parameters within the software in line with published guidelines (Moreira et al., 2017). Tsk was measured immediately distal to the thermistor using the spot measurement tool.

The same thermistor was used for each participant and checked for accuracy before experimental use at eight water temperatures $\left(5^{\circ} \mathrm{C}\right.$ to $40{ }^{\circ} \mathrm{C}$, at increments of $\left.5{ }^{\circ} \mathrm{C}\right)$. The thermistor was held at these temperatures in a precision water bath (Grant Instruments, UK) and compared to a UKAS calibrated precision digital thermometer (T600, Digitron Ltd, UK). Across the temperature range, the thermistor deviated by 0.11 $(0.03){ }^{\circ} \mathrm{C}$ from the UKAS calibrated precision digital thermometer.

\section{Statistical Analysis}

The difference in $T_{s k}$ following hand immersion was evaluated with a repeatedmeasures analysis of variance with Tukey's tests for multiple comparisons. Statistical significance was accepted at $\alpha<0.05$. Agreement between the infrared camera and thermistor was assessed by the mean difference (infrared camera minus thermistor) and $95 \%$ limits of agreement analysis, accounting for the repeated measures over time (Bland and Altman, 2007). The clinically significant threshold for $\mathrm{T}_{\text {sk }}$ differences was set at $0.5{ }^{\circ} \mathrm{C}$ (Bach et al., 2015a; Marins et al., 2014; Niu et al., 2001; Selfe et al., 2008). 
Therefore, an acceptable level of agreement would be a mean difference of $<0.5^{\circ} \mathrm{C}$ and $95 \%$ limits of agreement of $1^{\circ} \mathrm{C}$. 


\section{Results}

A statistically significant interaction was observed between the measurement devices over time $\left(\mathrm{F}_{9,459}=26.29, \mathrm{P}<0.001\right)$. Post-hoc analysis revealed the infrared camera was significantly higher than the thermistor at every minute during rewarming following hand immersion (Figure 1). As an average across all time points, the infrared camera recorded $\mathrm{T}_{\mathrm{sk}} 1.80(1.16){ }^{\circ} \mathrm{C}$ warmer than the thermistor, with $95 \%$ limits of agreement ranging from $-0.46{ }^{\circ} \mathrm{C}$ to $4.07^{\circ} \mathrm{C}$ (Figure 2). At no time point was the acceptable level of agreement met (Table 1). At each minute, and as an average, mean differences were outside the acceptable level of agreement (Table 1).

Table 1. Mean difference and $95 \%$ limits of agreement (LoA) for each time point and average

\begin{tabular}{c|cccc}
$\begin{array}{c}\text { Time } \\
(\mathbf{m i n})\end{array}$ & $\begin{array}{c}\text { Mean Difference } \\
\left({ }^{\circ} \mathbf{C}\right)\end{array}$ & $\begin{array}{c}\text { Standard Deviation } \\
\left({ }^{\circ} \mathbf{C}\right)\end{array}$ & $\begin{array}{c}\text { Lower } 95 \% \\
\text { LoA }\left({ }^{\circ} \mathbf{C}\right)\end{array}$ & $\begin{array}{c}\text { Upper } 95 \% \\
\text { LoA }\left({ }^{\circ} \mathbf{C}\right)\end{array}$ \\
\hline $\mathbf{1}$ & 2.55 & 1.32 & -0.04 & 5.14 \\
$\mathbf{2}$ & 2.56 & 1.19 & 0.22 & 4.90 \\
$\mathbf{3}$ & 2.43 & 1.38 & -0.27 & 5.14 \\
$\mathbf{4}$ & 2.04 & 1.12 & -0.15 & 4.23 \\
$\mathbf{5}$ & 1.85 & 1.12 & -0.35 & 4.04 \\
$\mathbf{6}$ & 1.61 & 0.99 & -0.32 & 3.54 \\
$\mathbf{7}$ & 1.38 & 0.88 & -0.34 & 3.11 \\
$\mathbf{8}$ & 1.24 & 0.65 & -0.03 & 2.51 \\
$\mathbf{9}$ & 1.23 & 0.68 & -0.10 & 2.57 \\
$\mathbf{1 0}$ & 1.15 & 0.66 & -0.14 & 2.43 \\
\hline Average & 1.80 & 1.16 & -0.46 & 4.07
\end{tabular}

Note: mean differences calculated as infrared camera minus thermistor. 


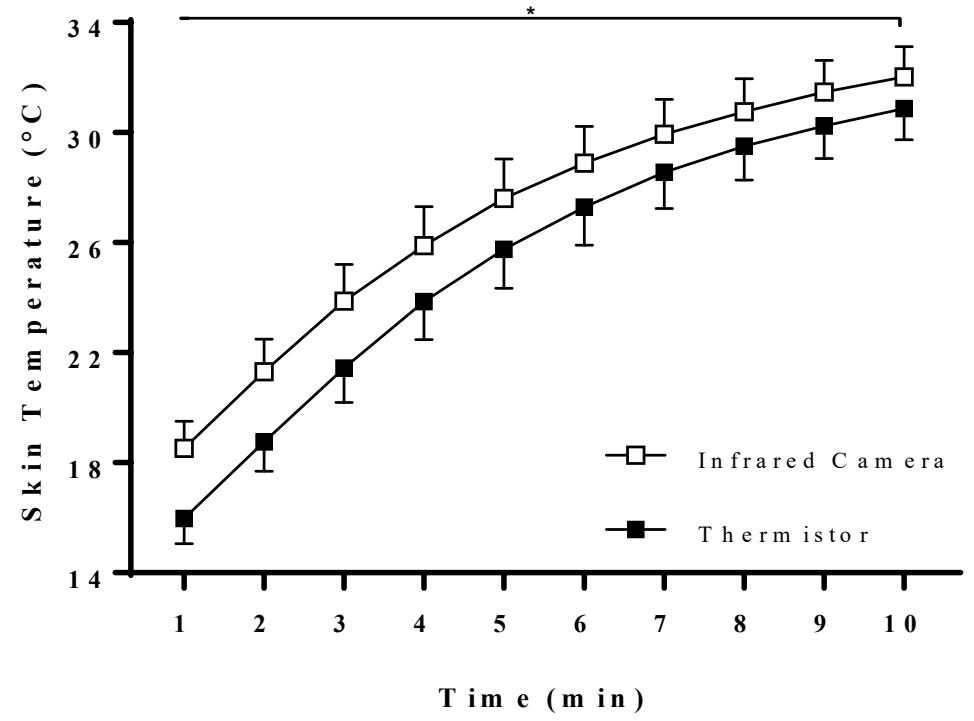

Figure 1. Mean (95\% confidence intervals) finger skin temperature measured by infrared camera and thermistor following cold exposure "statistical difference between the infrared camera and thermistor $(P<0.001)$. 
a

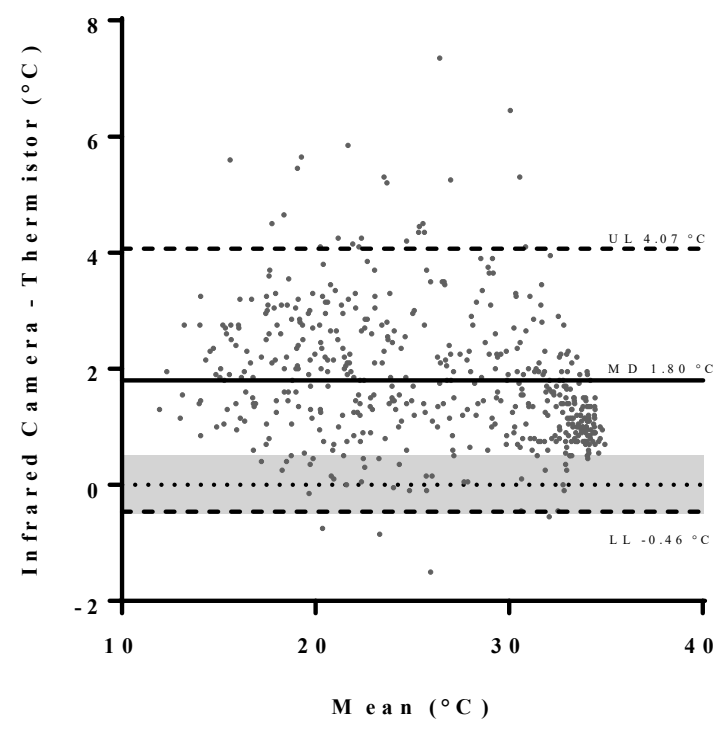

b

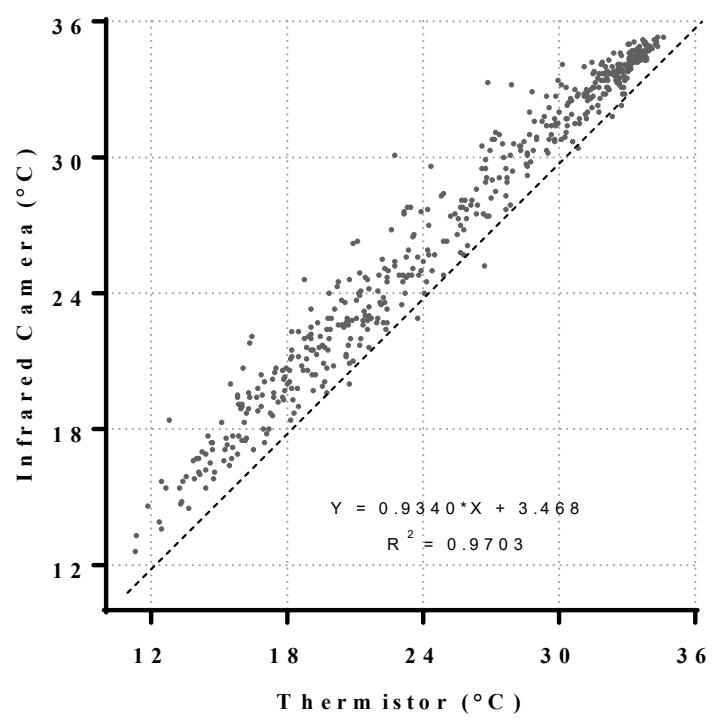

Figure 2. Scatterplot (a) and Bland-Altman plot (b) of the agreement between the infrared camera and thermistor for all time points

Note: MD, Mean difference; UL, Upper $95 \%$ limits of agreement; LL, Lower $95 \%$ limits of agreement. Grey band indicates a priori acceptable mean difference of $0.5^{\circ} \mathrm{C}$. 


\section{Discussion}

The primary aim of this study was to assess the accuracy of an infrared camera with that of a skin thermistor, both of which are commercially available. The study aimed to assess the agreement over a wide range of $T_{s k}$ following cold exposure; this was achieved as $\mathrm{T}_{\mathrm{sk}}$ ranged from $16{ }^{\circ} \mathrm{C}$ to $31^{\circ} \mathrm{C}$. Collectively, the results show the infrared camera overestimated $T_{\text {sk }}$ at every time point following local cooling (Figure 1). Further, measurement of $T_{\text {sk }}$ from the infrared camera consistently fell outside the acceptable level of agreement (i.e. mean difference $>0.5^{\circ} \mathrm{C}$ ) (Table 1, Figure 2b).

Few studies have previously assessed the accuracy of infrared devices with that of conductive devices during skin cooling. Buono et al. (2007) utilised a handheld infrared thermometer and contact thermistor to assess weighted mean $T_{\text {sk }}$ during rest at air temperatures of $15{ }^{\circ} \mathrm{C}$ and $25{ }^{\circ} \mathrm{C}$ in six participants. They reported no statistical difference in $T_{\text {sk }}$ between devices. Unfortunately, incomplete statistical analysis was conducted, preventing any meaningful interpretation of agreement between devices. Korukçu et al. (2009) tested facial $T_{\text {sk }}$ of three participants using an infrared camera and contact thermocouple during mild car cabin cooling. Similar to Buono et al. (Buono et al., 2007), small sample size and inadequate statistical analysis were conducted preventing proper interpretation of agreement between devices, with authors summarising results of $a<2{ }^{\circ} \mathrm{C}$ difference between the two devices. Finally, Kelechi et al. (2011) recruited 17 participants and compared a handheld infrared device with a thermistor during local skin cooling of the legs. Following cooling, most measurements (71\%) had a mean difference of $>0.5{ }^{\circ} \mathrm{C}$ between devices. However, raw $\mathrm{T}_{\mathrm{sk}}$ values are not provided which, similar to previous studies, makes interpretation of results difficult. 
To the authors' knowledge, this is the first study to assess the agreement between infrared and conductive devices over a wide range of cool $T_{\text {sk }}$ during a dynamic situation using a large sample. In this study, the infrared camera overestimated $T_{\text {sk }}$ compared with the contact thermistor, which may have safety implications. As aforementioned, infrared devices have been used to measure $\mathrm{T}_{\text {sk }}$ following cryotherapy (Costello et al., 2012a, 2012b; Selfe et al., 2014) and assess injury severity in NFCl patients (Ahle et al., 1990; Eglin et al., 2013; Thomas and Oakley, 2001). Cooling $\mathrm{T}_{\mathrm{sk}}$ to $<15{ }^{\circ} \mathrm{C}$ for a prolonged period exposes an individual to local cold injuries, such as NFCl (Eglin et al., 2013; House et al., 2000; Maley et al., 2017, 2014; Thomas and Oakley, 2001). Thus, if a study uses an infrared camera to assess $T_{\text {sk }}$ during or following cooling there is an increased risk of exposing that individual to lower than expected skin temperatures that may lead to $\mathrm{NFCl}$. The authors are aware $\mathrm{T}_{\text {sk }}$ within this study did not reach $<15{ }^{\circ} \mathrm{C}$ but we can only speculate that the mean difference between devices would also be different at these lower skin temperatures.

The present study is not without limitations. Within the infrared camera software, the spot tool was chosen to record $\mathrm{T}_{\mathrm{sk}}$, which was distal to the contact thermistor location; meaning there was a difference in the location where $T_{\text {sk }}$ was measured from. However, the authors are confident that the difference of around $1 \mathrm{~cm}$ between device measurement locations is not the reason for the overestimation of $T_{\text {sk }}$ from the infrared camera (Maniar et al., 2015). The authors considered the possibility the contact thermistor was experiencing substantial thermal inertia, which may have explained why the thermistor consistently measured cooler $T_{\text {sk }}$ compared with the infrared device. 
However, based on pilot studies, the response rate of the thermistor $\left(\Delta 15^{\circ} \mathrm{C} \cdot \mathrm{min}^{-1}\right)$ used far exceeds $\mathrm{T}_{\mathrm{sk}}$ rewarming rates in this study.

\section{Conclusion}

In conclusion, the infrared camera utilised in this study overestimated $T_{\text {sk }}$ between $16{ }^{\circ} \mathrm{C}$ and $31{ }^{\circ} \mathrm{C}$. Future research should consider using contact devices, checked for accuracy against a UKAS calibrated thermometer, in order to report accurate $T_{\text {sk }}$ and to reduce the potential risk of peripheral cold injuries. Future research is needed to compare infrared and contact devices where $\mathrm{T}_{\mathrm{sk}}$ is $<15^{\circ} \mathrm{C}$. 


\section{Acknowledgements}

The authors thank the participants for their time and commitment to this study. The authors declare no conflicts of interest.

\section{Funding}

This research did not receive any specific grant from funding agencies in the public, commercial, or not-for-profit sectors.

\section{Ethical Statement}

This study was given ethical approval from the University of Portsmouth Science Faculty Ethics Committee and complied with standards set in The Declaration of Helsinki (2013). The participants were made aware of the purpose, procedures and risks of the study before giving their informed written consent. 


\section{References}

Ahle, N.W., Buroni, J.R., Sharp, M.W., Hamlet, M.P., 1990. Infrared thermographic measurement of long term circulatory compromise in trenchfoot injured Argentine soldiers. Aviat. Sp. Environ. Med. 61, 247-250.

Bach, A.J.E., Stewart, I.B., Disher, A.E., Costello, J.T., 2015a. A comparison between conductive and infrared devices for measuring mean skin temperature at rest, during exercise in the heat, and recovery. PLoS One 10, 1-13. https://doi.org/10.1371/journal.pone.0117907

Bach, A.J.E., Stewart, I.B., Minett, G.M., Costello, J.T., 2015b. Does the technique employed for skin temperature assessment alter outcomes? A systematic review. Physiol. Meas. 36, R27-R51. https://doi.org/10.1088/0967-3334/36/9/R27

Bland, J.M., Altman, D.G., 2007. Agreement between methods of measurement with multiple observations per individual. J. Biopharm. Stat. 17, 571-582. https://doi.org/10.1080/10543400701329422

Brändström, H., Grip, H., Hallberg, P., Grönlund, C., Ängquist, K.-A., Giesbrecht, G.G., 2008. Hand cold recovery responses before and after 15 months of military training in a cold climate. Aviat. Space. Environ. Med. 79, 904-908. https://doi.org/10.3357/ASEM.1886.2008

Bull, K., 2008. Thermistors and thermocouples: matching the tool to the task in thermal validation. J. Valid. Technol. 14, 73-76.

Buller, M.J., Welles, A.P., Friedl, K.E., 2018. Wearable Physiological Monitoring for 
Human Thermal-Work Strain Optimization. J. Appl. Physiol. 124, 432-441. https://doi.org/10.1152/japplphysiol.00353.2017

Buono, M.J., Jechort, A., Marques, R., Smith, C., Welch, J., 2007. Comparison of infrared versus contact thermometry for measuring skin temperature during exercise in the heat. Physiol. Meas. 28, 855-859. https://doi.org/10.1088/0967$3334 / 28 / 8 / 008$

Burton, A.C., 1935. Human Calorimetry: II. The Average Temperature of the Tissues of the Body. J. Nutr. 9, 261-280.

Costello, J.T., Culligan, K., Selfe, J., Donnelly, A.E., 2012a. Muscle, Skin and Core Temperature after $-110^{\circ} \mathrm{C}$ Cold Air and $8^{\circ} \mathrm{C}$ Water Treatment. PLoS One 7, e48190.

Costello, J.T., Mclnerney, C.D., Bleakley, C.M., Selfe, J., Donnelly, A.E., 2012b. The use of thermal imaging in assessing skin temperature following cryotherapy: a review. J. Therm. Biol. 37, 103-110. https://doi.org/10.1016/j.jtherbio.2011.11.008

Eglin, C.M., Golden, F.S.C., Tipton, M.J., 2013. Cold sensitivity test for individuals with non-freezing cold injury: the effect of prior exercise. Extrem. Physiol. Med. 2, 16. https://doi.org/10.1186/2046-7648-2-16

Fenemor, S.P., Gill, N.D., Sims, S.T., Beaven, C.M., Driller, M.W., 2019. Validity of a Tympanic Thermometer and Thermal Imaging Camera for Measuring Core and Skin Temperature during Exercise in the Heat. Meas. Phys. Educ. Exerc. Sci. 1-7. https://doi.org/10.1080/1091367X.2019.1667361 
Fernández-Cuevas, I., Bouzas Marins, J.C., Arnáiz Lastras, J., Gómez Carmona, P.M., Piñonosa Cano, S., García-Concepción, M.Á., Sillero-Quintana, M., 2015. Classification of factors influencing the use of infrared thermography in humans: A review. Infrared Phys. Technol. https://doi.org/10.1016/j.infrared.2015.02.007

Hardy, J.D., Du Bois, E.F., 1938. The technic of measuring radiation and convection. J. Nutr. 15, 461-475.

Hildebrandt, C., Raschner, C., Ammer, K., 2010. An overview of recent application of medical infrared thermography in sports medicine in Austria. Sensors 10, 47004715. https://doi.org/10.3390/s100504700

Hope, K., Eglin, C.M., Golden, F., Tipton, M., 2014. Sublingual glyceryl trinitrate and the peripheral thermal responses in normal and cold-sensitive individuals. Microvasc. Res. 91, 84-89. https://doi.org/10.1016/j.mvr.2013.11.002

House, C.M., House, J.R., Oakley, E.H., 2000. Findings from a simulated disabled submarine survival trial. Undersea Hyperb. Med. 27, 175-183.

Hunt, A.P., Stewart, I.B., Billing, D.C., 2019. Indices of physiological strain for firefighters of the Australian Defence Forces. J. Occup. Environ. Hyg. 16, 727-734. https://doi.org/10.1080/15459624.2019.1666211

James, C.A., Richardson, A.J., Watt, P.W., Maxwell, N.S., 2014. Reliability and validity of skin temperature measurement by telemetry thermistors and a thermal camera during exercise in the heat. J. Therm. Biol. 45, 141-149. https://doi.org/10.1016/j.jtherbio.2014.08.010 
Jay, O., Reardon, F.D., Webb, P., Ducharme, M.B., Ramsay, T., Nettlefold, L., Kenny, G.P., 2007. Estimating changes in mean body temperature for humans during exercise using core and skin temperatures is inaccurate even with a correction $\begin{array}{llll}\text { factor. } & \text { J. }\end{array}$ https://doi.org/10.1152/japplphysiol.00117.2007

Kelechi, T.J., Good, A., Mueller, M., 2011. Agreement and repeatability of an infrared thermometer. J. Nurs. Meas. 19, 55-64. https://doi.org/10.1891/1061-3749.19.1.55

Korukçu, M.Ö., Kilic, M., 2009. The usage of IR thermography for the temperature measurements inside an automobile cabin. Int. Commun. Heat Mass Transf. 36, 872-877. https://doi.org/https://doi.org/10.1016/j.icheatmasstransfer.2009.04.010

Maley, M.J., Eglin, C.M., House, J.R., Tipton, M.J., 2014. The effect of ethnicity on the vascular responses to cold exposure of the extremities. Eur. J. Appl. Physiol. 114, 2369-2379. https://doi.org/10.1007/s00421-014-2962-2

Maley, M.J., House, J.R., Tipton, M.J., Eglin, C.M., 2017. Role of cyclooxygenase in the vascular responses to extremity cooling in Caucasian and African males. Exp. Physiol. 102, 854-865. https://doi.org/10.1113/EP086186

Maniar, N., Bach, A.J.E., Stewart, I.B., Costello, J.T., 2015. The effect of using different regions of interest on local and mean skin temperature. J. Therm. Biol. 49-50, 3338. https://doi.org/10.1016/j.jtherbio.2015.01.008

Marins, J.C.B., Fernandes, A.A., Cano, S.P., Moreira, D.G., da Silva, F.S., Costa, C.M.A., Fernandez-Cuevas, I., Sillero-Quintana, M., 2014. Thermal body patterns 
for healthy Brazilian adults (male and female). J. Therm. Biol. 42, 1-8. https://doi.org/10.1016/j.jtherbio.2014.02.020

Meola, C., Carlomagno, G.M., 2004. Recent advances in the use of infrared thermography. Meas. Sci. Technol. 15, R27-R58. https://doi.org/10.1088/09570233/15/9/R01

Mercer, J.B., Weerd, L. De, Miland, Å.O., Weum, S., 2010. Pre-, intra-, and postoperative use of dynamic infrared thermography (DIRT) provides valuable information on skin perfusion in perforator flaps used in reconstructive surgery, in: Inframation. Las Vegas, pp. 313-320.

Moreira, D.G., Costello, J.T., Brito, C.J., Adamczyk, J.G., Ammer, K., Bach, A.J.E., Costa, C.M.A., Eglin, C., Fernandes, A.A., Fernández-Cuevas, I., Ferreira, J.J.A., Formenti, D., Fournet, D., Havenith, G., Howell, K., Jung, A., Kenny, G.P., Kolosovas-Machuca, E.S., Maley, M.J., Merla, A., Pascoe, D., Priego-Quesada, J.I., Schwartz, R.G., Seixas, A.R.D., Selfe, J., Vainer, B.G., Sillero-Quintana, M., 2017. Thermographic imaging in sports and exercise medicine: a Delphi study and consensus statement on the measurement of human skin temperature. J. Therm. Biol. 69, 155-162. https://doi.org/10.1016/j.jtherbio.2017.07.006

Niu, H.H., Lui, P.W., Hu, J.S., Ting, C.K., Yin, Y.C., Lo, Y.L., Liu, L., Lee, T.Y., 2001. Thermal symmetry of skin temperature: normative data of normal subjects in Taiwan. Zhonghua Yi Xue Za Zhi (Taipei). 64, 459-468.

Ring, E.F.J., Ammer, K., 2012. Infrared thermal imaging in medicine. Physiol. Meas. 33, 
R33-R46. https://doi.org/10.1088/0967-3334/33/3/R33

Selfe, J., Alexander, J., Costello, J.T., May, K., Garratt, N., Atkins, S., Dillon, S., Hurst, H., Davison, M., Przybyla, D., Coley, A., Bitcon, M., Littler, G., Richards, J., 2014. The effect of three different $\left(-135^{\circ} \mathrm{C}\right)$ whole body cryotherapy exposure durations on elite rugby league players. PLoS One 9, 1-9. https://doi.org/10.1371/journal.pone.0086420

Selfe, J., Whitaker, J., Hardaker, N., 2008. A narrative literature review identifying the minimum clinically important difference for skin temperature asymmetry at the knee. Thermol. Int. 18, 51-54.

Shepherd, A.I., Costello, J.T., Bailey, S.J., Bishop, N., Wadley, A.J., Young-Min, S., Gilchrist, M., Mayes, H., White, D., Gorczynski, P., Saynor, Z.L., Massey, H., Eglin, C.M., 2019. "Beet" the cold: beetroot juice supplementation improves peripheral blood flow, endothelial function, and anti-inflammatory status in individuals with Raynaud's phenomenon. J. Appl. Physiol. 127, 1478-1490. https://doi.org/10.1152/japplphysiol.00292.2019

Thomas, J.R., Oakley, H.N., 2001. Nonfreezing cold injury, in: Pandolf, K.B., Burr, R.E. (Eds.), Medical Aspects of Harsh Environments. Volume 1. TMM Publications, Washington, D.C., pp. 467-490.

Togawa, T., 1989. Non-contact skin emissivity: measurement from reflectance using step change in ambient radiation temperature. Clin. Phys. Physiol. Meas. 10, 3948. 
